Academic Platform Journal of Engineering and Science

journal homepage: http://apjes.com/

\title{
Çok Katlı Betonarme Binalarda 2018 Deprem Yönetmeliği İle Tanımlanan Spektrum Eğrilerinin Etkisi
}

\author{
*1Y Yusuf Sümer, ${ }^{2}$ Mehtap Hamsici \\ ${ }^{1}$ Sakarya Uygulamalı Bilimler Üniversitesi, ysumer@subu.edu.tr, \\ ${ }^{2}$ mehtaphmsc@gmail.com,
}

Araștırma Makalesi

Geliş Tarihi: 01.11.2019

Kabul Tarihi: 27.03.2020

$\ddot{O} z$

01 Ocak 2019'da yürürlüğe giren Türkiye Bina Deprem Yönetmeliği (TBDY-2018) ile yapılan değişikliklerin en önemlilerinden biri deprem yer hareketi spektrum hesabının, yapının bulunduğu konuma ve zemin değerlerine göre yapılacak olmasıdır. Bu çalışmanın amacı, spektrum eğrilerinin hesabındaki bu önemli değişikliğin, yapıya gelen kuvvet ve yapıda meydana gelen deplasman değerlerindeki değişime etkisini araştırmaktır. Çalışmanın ilk bölümünde, her iki yönetmeliğe göre (TBDY-2018 ve Türk Deprem Yönetmeliği 2007 (TDY-2007)), taban kesme kuvveti ve maksimum göreli kat ötelemelerinin hesap esasları ile ilgili genel bilgiler verilmiştir. Sayısal analizler için öncelikle 1996 tarihli deprem tehlike haritasında sırasıyla 1., 2 ., 3. ve 4. bölgede yer alan Sakarya-Serdivan, Kocaeli-Kandıra, Eskişehir-Sivrihisar ve Ankara-Yenimahalle konumları belirlenmiştir. Belirlenen her konumda 4 farklı zemin cinsi dikkate alınarak üç adet farklı kat sayılarına sahip (4, 7 ve 10 katlı) yapılar oluşturulmuştur. Tasarım depremi altında IDECAD programı yardımıyla, TBDY-2018 ve TDY-2007 yönetmelikleri hesap esaslarına göre, belirlenen yapıların analizleri gerçekleştirilmiştir. Analizler sonucunda elde edilen taban kesme kuvvetleri ve maksimum göreli kat ötelemeleri tablo ve grafiklerle sunulmuştur. Elde edilen sonuçlara göre taban kesme kuvvetinin, kat sayısı arttıkça eski yönetmeliğe kıyasla daha düşük değerler verdiği, maksimum etkin göreli kat ötelemelerinin her yükseklikteki binada özellikle zemin değerleri olumsuz şartlara doğru gittikçe eski yönetmeliğe nazaran çok daha büyük değerler verdiği görülmüştür.

Anahtar Kelimeler: Taban kesme kuvveti, Göreli kat ötelemesi, TBDY-2018, Elastik tasarım spektral ivmesi, TDY-2007

\section{The Effect Of Spectrum Curves Defined By The Turkish Building Code 2018 On Multi-Storey Reinforced Concrete Buildings}

\author{
${ }^{* 1}$ Yusuf Sümer, ${ }^{2}$ Mehtap Hamsici \\ ${ }^{1}$ Sakarya Uygulamalı Bilimler Üniversitesi, ysumer@subu.edu.tr \\ ${ }^{2}$ mehtaphmsc@gmail.com
}

\begin{abstract}
New Turkish Building Earthquake Code (TBDY-2018) has come into force on 01 January 2019 and one of the most important innovation brought by the regulation is the calculation of earthquake ground spectra, according to location of the building and its ground parameters. Purpose of this study is to investigate the effects of this important modification on the forces acting on the structure and the change in the displacement values occurring in the structure. In the first part of the study, according to both regulations (TDBY-2018 and Turkish Earthquke Code 2007 (TDY-2007)), principles of base shear force and the maximum relative storey drifts of buildings are given. For numerical analysis, Sakarya-Serdivan, Kocaeli-Kandıra, Eskişehir-Sivrihisar and Ankara-Yenimahalle locations were determined in the earthquake hazard map of 1996, respectively in the 1st, 2nd, 3rd and 4th earthquake regions. Considering 4 different soil types in each designated location, three different storey buildings (4, 7 and 10 floors) have been created. Analyses were performed according to TBDY-2018 and TDY-2007 for the design earthquake with the help of IDECAD structural analysis program. Thus obtained structure base shear forces and relative storey drift values presented with tables and graphs. According to the results, it was observed that the base shear forces gives lower values compared to the old building code as the number of storey increases, and the maximum relative storey drift gives much higher values than the old building code, especially when the soil types changes from hard to soft conditions.
\end{abstract}

Keywords: Base shear force, Relative storey drift, TBDY-2018, Earthquake ground spectra, TDY-2007. 


\section{GÍRIŞ}

18.03.2018 tarihinde Resmi Gazetede yayınlanan ve 01.01.2019 tarihinde yürürlüğe giren Türkiye Bina Deprem Yönetmeliği ile Türkiye'nin deprem tehlike haritası tamamen yenilenmiş, deprem bölgeleri sınıflandırması kaldırılmıştır [1]. Deprem yönetmeliğindeki bu değişikliklerle birlikte zemin cinsinden kaynaklanan ivme katsayıları değişmiştir. Bundan dolayı kat ötelemelerini belirleyen, spektrum karakteristik periyotları ve dolayısıyla spektrum eğrilerindeki değişiklikler beraberinde gelmiştir. Bunun sonucunda yapıya gelen deprem kuvvetleri ve ötelemeler de değişmiştir. Bu konu üzerine yapılan çalışmalar henüz çok yetersizdir. Yapılan çalışmaların bazılarında TBDY-2018 yönetmeliği, spektral ivme değerleri, taban kesme kuvveti, bazılarında ise maksimum göreli kat ötelemesi açısından farklı il ve zemin cinsleri bazında eski yönetmelik ile karşılaştırılmıştır [2-9]. Yapısal analiz programlarının çok yakın bir zamanda yeni yönetmeliğin esaslarına göre analize imkan tanımasıyla birlikte bu değerlerin hepsinin birden farklı bina yüksekliklerinde, eski yönetmeliğe nazaran nasıl bir değişime uğrayacağını karşılaştırmak ve daha sağlıklı sonuçlar elde edebilmek, çalışmamızın amacını oluşturmuştur.

$\mathrm{Bu}$ çalışmada öncelikle süneklik düzeyi yüksek kolon ve perdelerden oluşan taşıyıcı sisteme sahip, her iki yönde simetrik, dört dairenin bulunduğu örnek bir kat planı tasarlanmıştır. Bu plan 4, 7 ve 10 katlı olarak düşünülerek taşıyıcı sistem elemanları buna göre 3 farklı şekilde belirlenmiştir. Bütün binalar için radye temel sistemi kullanılmıştır. 1996 Türkiye deprem bölgeleri haritasına göre [10] sirasiyla 1., 2., 3. ve 4. deprem bölgesinde yer alan Sakarya-Serdivan, Kocaeli-Kandıra, Eskişehir-Sivrihisar, Ankara-Yenimahalle ilçelerinde, TDY-2007'de tanımlanan [11] ve TBDY-2018'de de DD-2 tasarım depremi olarak yerini koruyan, 50 yılda aşılma olasılığı \%10 olan şiddetli deprem etkisi için, 4 farklı konum ve her konumda 4 farklı zemin sınıfı dikkate alınarak binaların her iki yönetmeliğe göre spektrum eğrileri elde edilmiştir. IDECAD [12] programı yardımı ile yapılan deprem analizleri sonucunda yapı doğal titreşim periyotları, spektrum katsayıları, taban kesme kuvvetleri ve kat içindeki en büyük etkin göreli kat ötelemesi değerleri karşılaştırılmıştır.

\section{BINA ANALIZLERINDE KULLANILAN PARAMETRELER}

\subsection{Spektrum Eğrilerinin Elde Edilmesi}

TDY-2007'de spektrum eğrisinin apsisi periyodu (T) ordinatı spektrum katsayısını $(\mathrm{S}(\mathrm{T})$ ) göstermektedir (Şekil 1a).

Burada $S(T)$ yerel zemin koşullarına $\left(T_{A}\right.$ ve $\left.T_{B}\right)$ ve bina doğal titreşim periyodu T'ye bağlı olarak Denklem 1,2 veya 3 ile hesaplanmaktadir.

$S(T)=1+1,5 \frac{T}{T_{A}} \quad\left(0 \leq \mathrm{T} \leq \mathrm{T}_{\mathrm{A}}\right)$

$$
\begin{aligned}
& S(T)=2,5 \quad\left(\mathrm{~T}_{\mathrm{A}}<\mathrm{T} \leq \mathrm{T}_{\mathrm{B}}\right) \\
& S(T)=2,5\left(\frac{T_{B}}{T}\right)^{0,8} \quad\left(\mathrm{~T}_{\mathrm{B}}<\mathrm{T}\right)
\end{aligned}
$$

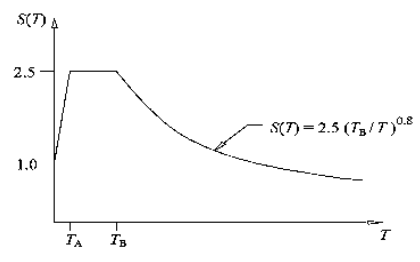

a)

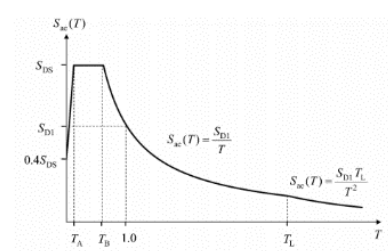

b)
Şekil 1. TDY-2007'de (a) ve TBDY-2018'de (b) tanımlanan spektrum eğrileri

TBDY-2018'e göre oluşturulan yatay elastik spektrum eğrisinin ordinatı $\left(\mathrm{S}_{\mathrm{ae}}(\mathrm{T})\right)$ yatay elastik tasarım spektral ivmesini göstermektedir (Şekil 1b). "S $\mathrm{S}_{\mathrm{ae}}(\mathrm{T})$ )", doğal titreşim periyoduna ve tasarım spektral ivme katsayılarına $\left(\mathrm{S}_{\mathrm{DS}}\right.$ ve $\mathrm{S}_{\mathrm{D} 1}$ ) bağlı olarak yerçekimi ivmesi (g) cinsinden tanımlanmıştır. Tasarım spektral ivme katsayıları ise harita spektral ivme katsayıları $\left(S_{S}\right.$ ve $\left.S_{1}\right)$ ile yerel zemin etki katsayılarının ( $F_{S}$ ve $\left.F_{1}\right)$ çarpımıyla elde edilmektedir. Burada harita spektral ivme katsayıları " $\mathrm{S}_{\mathrm{S}}$ " ve "S $\mathrm{S}_{1}$ " dört farklı deprem yer hareketi düzeyi için konum koordinatlarına bağlı olarak Türkiye Deprem Tehlike Haritalarında tanımlanmıştır. Yerel zemin etki katsayıları " $F_{S}$ " ve " $F_{1}$ " ise yerel zemin sınıfına bağlı olarak tablo halinde yönetmelikte verilmiştir [1].

\subsection{Yapı Konumlarının Belirlenmesi}

Bu çalışmada, deprem analizi yapılan binalar için, TDY2007'ye göre sirasiyla 1., 2., 3. ve 4. deprem bölgesinde yer alan Sakarya-Serdivan, Kocaeli-Kandıra, EskişehirSivrihisar, Ankara-Yenimahalle konumları tercih edilmiştir. $\mathrm{Bu}$ konumların deprem haritalarındaki yerleri Şekil 2'de, 1996 ve 2018 Deprem Haritalarında gösterilmiştir.

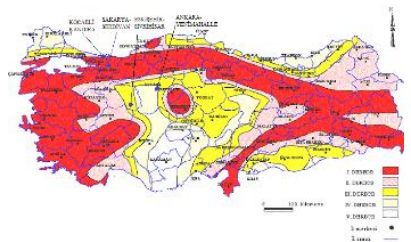

Türkiye Deprem Bölgeleri Haritas1, 1996 [7] Haritas1, 2018 [13]

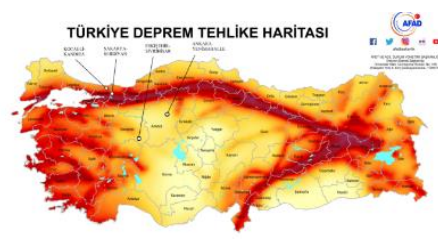

Türkiye Deprem Tehlike

\subsection{Zemin Cinsi}

Zeminler, TDY-2007'de 4 farklı zemin grubuna ve bunların en üst zemin tabakası kalınlığına göre $Z 1, Z 2, Z 3$ ve $Z 4$ olmak üzere 4 yerel zemin sınıfına ayrılmıştır. TBDY2018 'de ise bu sinıflandırma, zeminin üst $30 \mathrm{~m}$ ortalamas alınarak ZA, ZB, ZC, ZD, ZE ve ZF olmak üzere 6 sınıf olacak şekilde tanımlanmıştır. Bu çalışmada, TDY-2007 ve TBDY-2018'e göre deprem analizini yapılan binalarda aynı zamanda zemin cinsindeki değişimin de spektrum katsayısı, 
taban kesme kuvveti ve en büyük kat ötelemelerine etkisini görebilmek için 4 farklı zemin sınıfı kullanılmıştır. Bunlar her iki yönetmelikte karşılıklı olarak ZA ve Z1 (sağlam kaya ve kayaçlar), ZC ve Z2 (çok çatlaklı zayıf kaya, çakıl), ZD ve Z3 (orta sıkı kum, katı kil), ZE ve Z4 (gevşek kum, yumuşak kil) zemin sınıflarıdır.

\subsection{Yapı Özellikleri}

Normal kat kalıp planı Şekil 3'te gösterilen binalar, zemin kat yüksekliği 3,00 m ve normal kat yüksekliği 2,80 m olarak tasarlanmıştır. Binaların toplam kat yüksekliği; 4 katlı binalarda $11,40 \mathrm{~m}, 7$ katlı binalarda $19,80 \mathrm{~m}$ ve 10 katlı olarak 28,20 m olmuştur. Normal kat alanı brüt $610 \mathrm{~m}^{2}$, net $565 \mathrm{~m}^{2}$ olup, iki yönde simetrik olan binanın her bir katında 4 daire bulunmaktadır.

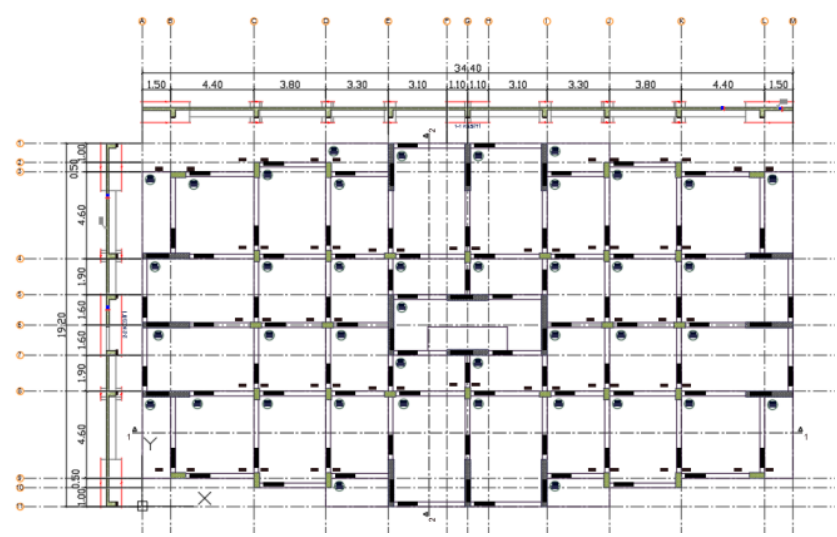

Şekil 3. Normal Kat Kalıp Planı

Binaların taşıyıcı eleman boyutları kat sayısıyla orantılı şekilde arttırılmış olup yaygın olarak kullanılan süneklik düzeyi yüksek betonarme çerçeve ile süneklik düzeyi yüksek boşluksuz betonarme perdelerden oluşan taşıyıcı sistem tercih edilmiştir. 3 farklı bina yüksekliğinde kullanılan taşıyıcı eleman özellikleri Tablo 1'de verilmiştir.

\subsection{Analizlerde Kullanılan Parametreler}

Analizlerde beton sınıfı C30/37, çelik sınıfı B420C (S420) seçilmiştir. Deprem yer hareketi düzeyi olarak, TBDY2018'e göre yapılan bütün analizlerde standart tasarım deprem yer hareketi olarak da adlandırılan DD-2 Deprem Yer Hareketi seçilmiştir. Bina önem katsayısı (I) yapı türü konut olduğu için her iki yönetmeliğe göre yapılan bütün analizlerde 1 alınmıştır. Dayanım fazlalığı katsayısı (D) TBDY-2018'e göre yapılan bütün analizlerde her iki yönde 2,5 alınmıştır. TBDY-2018'e göre yapılacak olan analizlerde, Deprem Tasarım Sınıfı (DTS), Bina Kullanım Sinıflarına (BKS) ve Kısa Periyot Tasarım Spektral İvme katsayısına bağlı olarak yönetmelikteki tablodan alınmıştır.
TBDY-2018'e göre Bina Yükseklik Sınıfı (BYS), bina yüksekliğine ve Deprem Tasarım Sınıfına bağlı olarak yönetmelikteki tablodan alınmıştır.

Tablo 1. Binaların Taşıyıcı Sistem Geometrik Özellikleri

\begin{tabular}{|c|c|c|c|}
\hline yön & 4 Katlı & 7 Katl1 & 10 Katl1 \\
\hline 흐 $\stackrel{\bar{E}}{\Xi} \mathrm{x}$ & $\begin{array}{l}4 \text { adet } 30 / 80 \mathrm{~cm} \\
8 \text { adet } 30 / 60 \mathrm{~cm}\end{array}$ & 12 adet $30 / 70 \mathrm{~cm}$ & $0 / 80 \mathrm{~cm}$ \\
\hline م. & $\begin{array}{c}8 \text { adet } 30 / 80 \mathrm{~cm} \\
10 \operatorname{adet} 30 / 60 \mathrm{~cm}\end{array}$ & $\begin{array}{c}8 \text { adet } 30 / 80 \mathrm{~cm} \\
10 \operatorname{adet} 30 / 70 \mathrm{~cm} \\
\end{array}$ & $18 \mathrm{ad}$ \\
\hline 巳一 & $\begin{array}{l}6 \text { adet } 30 / 250 \mathrm{~cm} \\
2 \text { adet } 30 / 220 \mathrm{~cm}\end{array}$ & $\begin{array}{l}6 \text { adet } 30 / 250 \mathrm{~cm} \\
2 \text { adet } 30 / 220 \mathrm{~cm}\end{array}$ & $\begin{array}{l}6 \text { adet } 30 / 250 \mathrm{~cm} \\
2 \text { adet } 30 / 220 \mathrm{~cm}\end{array}$ \\
\hline 总 & $\begin{array}{l}6 \text { adet } 30 / 250 \mathrm{~cm} \\
2 \text { adet } 30 / 320 \mathrm{~cm}\end{array}$ & $\begin{array}{l}6 \text { adet } 30 / 250 \mathrm{~cm} \\
2 \operatorname{adet} 30 / 320 \mathrm{~cm}\end{array}$ & $\begin{array}{l}6 \text { adet } 30 / 250 \mathrm{~cm} \\
2 \operatorname{adet} 30 / 320 \mathrm{~cm} \\
\end{array}$ \\
\hline Kirişler & $25 / 50 \mathrm{~cm}$ & $25 / 60 \mathrm{~cm}$ & $30 / 60 \mathrm{~cm}$ \\
\hline
\end{tabular}

\section{BİNA ANALIZ SONUÇLARI}

TDY-2007'ye göre 4 farklı deprem bölgesinden seçilen konumlar üzerinde (Ankara-Yenimahalle, SivrihisarEskişehir, Kandıra-Kocaeli, Sakarya-Serdivan) 4 farklı zemin cinsinde (Z1-ZA, Z2-ZC, Z3-ZD, Z4-ZE) tasarlanan 4 katlı, 7 katlı ve 10 katlı konut türündeki yapıların, TBDY2018 ve TDY-2007'ye göre IDECAD programıla yapılan deprem analizleri sonucunda, binalara gelen taban kesme kuvvetlerini belirleyen spektrum karakteristik periyotları, yapı doğal titreşim periyotları, spektrum katsayıları Tablo 2' de gösterilmiştir. Tablo 2'de, Yenimahalle=YM, Sivrihisar $=\mathrm{SH}, \quad$ Kandıra $=\mathrm{K}$ ve Serdivan $=\mathrm{S}$ olarak kısaltılmıştır.

Tablo 2'de ayrıca spektrum katsayılarının karşılaştırmasını yapabilmek için TDY-2007'ye göre hesaplanan spektrum katsayıları, yerel zemin etki katsayısı $\left(\mathrm{A}_{\mathrm{o}}\right)$ ile çarpılmıştır.

Bina her iki yönden simetrik olmasına rağmen TBDY2018'e göre yapılan analizlerde A1 düzensizliği oluştuğundan göreli kat ötelemelerinin hesab1 $\pm \% 5$ ek diş merkezlik etkileri de göz önüne alınarak kat döşemeleri kendi düzlemleri içinde rijit kabul edilip modal analiz yapılmıştır. TDY-2007'ye göre yapılan analizde hiçbir düzensizlik oluşmamış ve modal analiz yapılmıştır.

Tabloda, yap1 doğal titreşim periyodu değeri, spektrum karakteristik periyotları $\left(\mathrm{T}_{\mathrm{A}}\right.$ ve $\left.\mathrm{T}_{\mathrm{B}}\right)$ arasında ise yani rezonans durumu oluşuyorsa kırmızıya, $\mathrm{T}_{\mathrm{B}}$ 'den büyük ise yeşile boyanmıştır. Yeni yönetmelikte binalar için olumsuz bu durumun azaldığı görülmüştür.

Yeni yönetmelikte spektrum karakteristik periyotlarının ve spektrum katsayılarının hesabındaki değişim, binaların taban kesme kuvvetlerinin aldığ 1 değerlerde farklı etkilere sebep olmuştur (Şekil 4-5-6). 
Tablo 2. Konum, zemin sınıfı ve kat adedine göre analiz sonuçları

\begin{tabular}{|c|c|c|c|c|c|c|c|c|c|}
\hline \multirow[b]{2}{*}{ Yap1 Tipi } & \multirow[b]{2}{*}{ Konum } & \multirow[b]{2}{*}{$\begin{array}{c}\text { Zemin } \\
\text { Sinıfi }\end{array}$} & \multicolumn{4}{|c|}{ TDY-2007 } & \multicolumn{3}{|c|}{ TBDY-2018 } \\
\hline & & & $\begin{array}{c}\mathbf{T}_{\mathrm{A}-\mathbf{T}_{\mathbf{B}}} \\
(\mathbf{s})\end{array}$ & $\mathbf{T}(\mathbf{s})$ & $\mathbf{S}(\mathbf{T})$ & $\mathbf{A}_{0} \times \mathbf{S}(\mathbf{T})$ & $\mathbf{T}_{\mathbf{A}}-\mathbf{T}_{\mathbf{B}}(\mathbf{s})$ & $\mathbf{T}(\mathbf{s})$ & $\mathbf{S}(\mathbf{T})$ \\
\hline \multirow{16}{*}{ 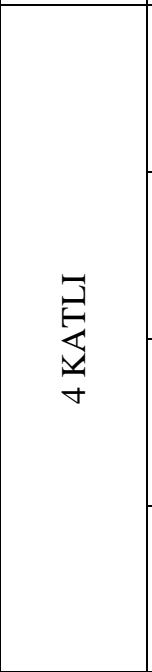 } & \multirow{4}{*}{ YM } & Z1-ZA & $0,10-0,30$ & 0,36 & 2,16 & 0,22 & $0,07-0,37$ & 0,51 & 0,20 \\
\hline & & Z2-ZC & $0,15-0,40$ & 0,36 & 2,50 & 0,25 & $0,09-0,43$ & 0,51 & 0,36 \\
\hline & & Z3-ZD & $0,15-0,60$ & 0,37 & 2,50 & 0,25 & $0,11-0,57$ & 0,52 & 0,51 \\
\hline & & Z4-ZE & $0,20-0,90$ & 0,37 & 2,50 & 0,25 & $0,14-0,68$ & 0,52 & 0,72 \\
\hline & \multirow{4}{*}{ SH } & Z1-ZA & $0,10-0,30$ & 0,36 & 2,16 & 0,43 & $0,05-0,26$ & 0,51 & 0,19 \\
\hline & & Z2-ZC & $0,15-0,40$ & 0,36 & 2,50 & 0,50 & $0,06-0,30$ & 0,51 & 0,36 \\
\hline & & Z3-ZD & $0,15-0,60$ & 0,37 & 2,50 & 0,50 & $0,09-0,43$ & 0,52 & 0,56 \\
\hline & & Z4-ZE & $0,20-0,90$ & 0,37 & 2,50 & 0,50 & $0,12-0,59$ & 0,52 & 0,84 \\
\hline & \multirow{4}{*}{$\mathrm{K}$} & Z1-ZA & $0,10-0,30$ & 0,36 & 2,16 & 0,64 & $0,06-0,31$ & 0,51 & 0,37 \\
\hline & & Z2-ZC & $0,15-0,40$ & 0,36 & 2,50 & 0,75 & $0,08-0,39$ & 0,51 & 0,69 \\
\hline & & Z3-ZD & $0,15-0,60$ & 0,37 & 2,50 & 0,75 & $0,11-0,55$ & 0,52 & 0,91 \\
\hline & & Z4-ZE & $0,20-0,90$ & 0,37 & 2,50 & 0,75 & $0,15-0,75$ & 0,52 & 0,98 \\
\hline & \multirow{4}{*}{$\mathrm{S}$} & Z1-ZA & $0,10-0,30$ & 0,36 & 2,16 & 0,86 & $0,05-0,26$ & 0,51 & 0,60 \\
\hline & & Z2-ZC & $0,15-0,40$ & 0,36 & 2,50 & 1,00 & $0,06-0,32$ & 0,51 & 1,12 \\
\hline & & Z3-ZD & $0,15-0,60$ & 0,37 & 2,50 & 1,00 & $0,10-0,49$ & 0,52 & 1,41 \\
\hline & & Z4-ZE & $0,20-0,90$ & 0,37 & 2,50 & 1,00 & $0,16-0,79$ & 0,52 & 1,20 \\
\hline \multirow{16}{*}{ 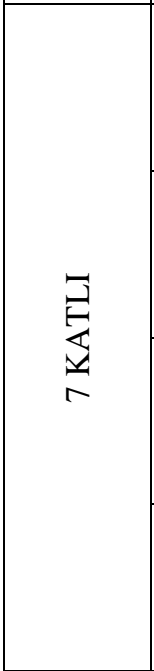 } & \multirow{4}{*}{ YM } & Z1-ZA & $0,10-0,30$ & 0,57 & 1,49 & 0,15 & $0,07-0,37$ & 0,82 & 0,12 \\
\hline & & Z2-ZC & $0,15-0,40$ & 0,58 & 1,87 & 0,19 & $0,09-0,43$ & 0,83 & 0,23 \\
\hline & & Z3-ZD & $0,15-0,60$ & 0,58 & 2,50 & 0,25 & $0,11-0,57$ & 0,83 & 0,35 \\
\hline & & Z4-ZE & $0,20-0,90$ & 0,59 & 2,50 & 0,25 & $0,14-0,68$ & 0,84 & 0,59 \\
\hline & \multirow{4}{*}{$\mathrm{SH}$} & Z1-ZA & $0,10-0,30$ & 0,57 & 1,49 & 0,30 & $0,05-0,26$ & 0,82 & 0,12 \\
\hline & & Z2-ZC & $0,15-0,40$ & 0,58 & 1,87 & 0,37 & $0,06-0,30$ & 0,83 & 0,22 \\
\hline & & Z3-ZD & $0,15-0,60$ & 0,58 & 2,50 & 0,50 & $0,09-0,43$ & 0,83 & 0,35 \\
\hline & & \begin{tabular}{|l|}
$\mathrm{Z} 4-\mathrm{ZE}$ \\
\end{tabular} & $0,20-0,90$ & 0,59 & 2,50 & 0,50 & $0,12-0,59$ & 0,84 & 0,59 \\
\hline & \multirow{4}{*}{ K } & Z1-ZA & $0,10-0,30$ & 0,57 & 1,49 & 0,45 & $0,06-0,31$ & 0,82 & 0,23 \\
\hline & & Z2-ZC & $0,15-0,40$ & 0,58 & 1,87 & 0,56 & $0,08-0,39$ & 0,83 & 0,43 \\
\hline & & Z3-ZD & $0,15-0,60$ & 0,58 & 2,50 & 0,75 & $0,11-0,55$ & 0,83 & 0,60 \\
\hline & & Z4-ZE & $0,20-0,90$ & 0,59 & 2,50 & 0,75 & $0,15-0,75$ & 0,84 & 0,88 \\
\hline & \multirow{4}{*}{$\mathrm{S}$} & Z1-ZA & $0,10-0,30$ & 0,57 & 1,49 & 0,60 & $0,05-0,26$ & 0,82 & 0,37 \\
\hline & & Z2-ZC & $0,15-0,40$ & 0,58 & 1,87 & 0,75 & $0,06-0,32$ & 0,83 & 0,69 \\
\hline & & Z3-ZD & $0,15-0,60$ & 0,58 & 2,50 & 1,00 & $0,10-0,49$ & 0,83 & 0,88 \\
\hline & & Z4-ZE & $0,20-0,90$ & 0,59 & 2,50 & 1,00 & $0,16-0,79$ & 0,84 & 1,12 \\
\hline \multirow{16}{*}{ 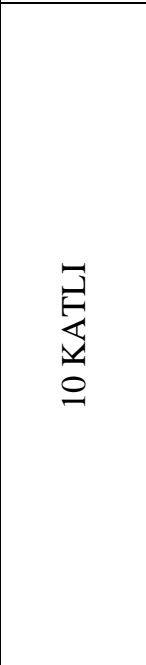 } & \multirow{4}{*}{ YM } & Z1-ZA & $0,10-0,30$ & 0,79 & 1,15 & 0,14 & $0,07-0,37$ & 1,15 & 0,09 \\
\hline & & Z2-ZC & $0,15-0,40$ & 0,80 & 1,44 & 0,14 & $0,09-0,43$ & 1,15 & 0,16 \\
\hline & & Z3-ZD & $0,15-0,60$ & 0,81 & 1,98 & 0,20 & $0,11-0,57$ & 1,16 & 0,25 \\
\hline & & Z4-ZE & $0,20-0,90$ & 0,81 & 2,50 & 0,25 & $0,14-0,68$ & 1,17 & 0,42 \\
\hline & \multirow{4}{*}{$\mathrm{SH}$} & Z1-ZA & $0,10-0,30$ & 0,79 & 1,15 & 0,23 & $0,05-0,26$ & 1,15 & 0,09 \\
\hline & & Z2-ZC & $0,15-0,40$ & 0,80 & 1,44 & 0,29 & $0,06-0,30$ & 1,15 & 0,16 \\
\hline & & Z3-ZD & $0,15-0,60$ & 0,81 & 1,98 & 0,39 & $0,09-0,43$ & 1,16 & 0,25 \\
\hline & & Z4-ZE & $0,20-0,90$ & 0,81 & 2,50 & 0,50 & $0,12-0,59$ & 1,17 & 0,42 \\
\hline & \multirow{4}{*}{ K } & Z1-ZA & $0,10-0,30$ & 0,79 & 1,15 & 0,35 & $0,06-0,31$ & 1,15 & 0,16 \\
\hline & & Z2-ZC & $0,15-0,40$ & 0,80 & 1,44 & 0,29 & $0,08-0,39$ & 1,15 & 0,31 \\
\hline & & Z3-ZD & $0,15-0,60$ & 0,81 & 1,98 & 0,43 & $0,11-0,55$ & 1,16 & 0,43 \\
\hline & & Z4-ZE & $0,20-0,90$ & 0,81 & 2,50 & 0,75 & $0,15-0,75$ & 1,17 & 0,63 \\
\hline & & \begin{tabular}{|l|} 
Z1-ZA \\
\end{tabular} & $0,10-0,30$ & 0,78 & 1,16 & 0,46 & $0,05-0,26$ & 1,14 & 0,27 \\
\hline & $\mathrm{S}$ & Z2-ZC & $0,15-0,40$ & 0,78 & 1,46 & 0,58 & $0,06-0,32$ & 1,14 & 0,50 \\
\hline & 3 & Z3-ZD & $0,15-0,60$ & 0,78 & 2,02 & 0,80 & $0,10-0,49$ & 1,14 & 0,64 \\
\hline & & Z4-ZE & $0,20-0,90$ & 0,78 & 2,50 & 1,00 & $0,16-0,79$ & 1,14 & 0,83 \\
\hline
\end{tabular}

Şekil 4'te dört katlı binaların taban kesme kuvvetlerine bakıldığında TDY-2007'ye göre aynı konumda, zemin sınıfı, güçlüden zayıfa doğru gittiği halde değerlerde kayda değer bir artış olmadığı, artışın sadece deprem bölgesi değişimlerinde yaşandığı, buna karşın 2018 yönetmeliğine göre yapılan analiz sonuçlarında zemin sınıfının aynı 
şekildeki değişimlerinde taban kesme kuvvetinin önemli artışlar gösterdiği görülmektedir. Ayrıca 2018 yönetmeliğinin taban kesme kuvveti sonuçlarına bakıldığında ZA-Z1 cinsinde 2007 yönetmeliğinden daha düşük değerler verdiği ZD-Z3, ZE-Z4 zemin sınıflarında ise daha yüksek değerlere ulaştığı görülmüştür.

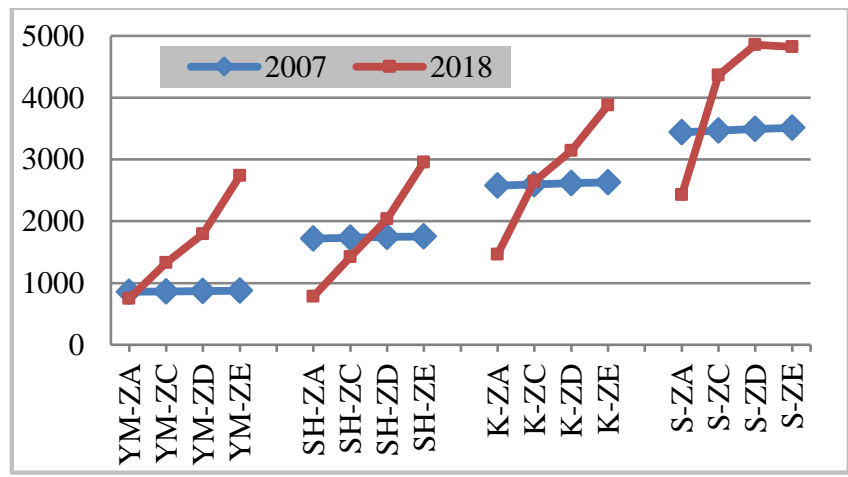

Şekil 4. Dört katlı binaların konum ve zemin cinsine bağlı değişen taban kesme kuvvetleri $(\mathrm{kN})$

Yedi katlı binalarda bütün konumlarda, ZE-Z4 zemin sınıflarında, 2018 yönetmeliğiyle bulunan taban kesme kuvvetleri, 2007 yönetmeliğinden daha büyük, ZA-Z1 zemin sınıflarında ise daha küçük olduğu görülmektedir (Şekil 5).

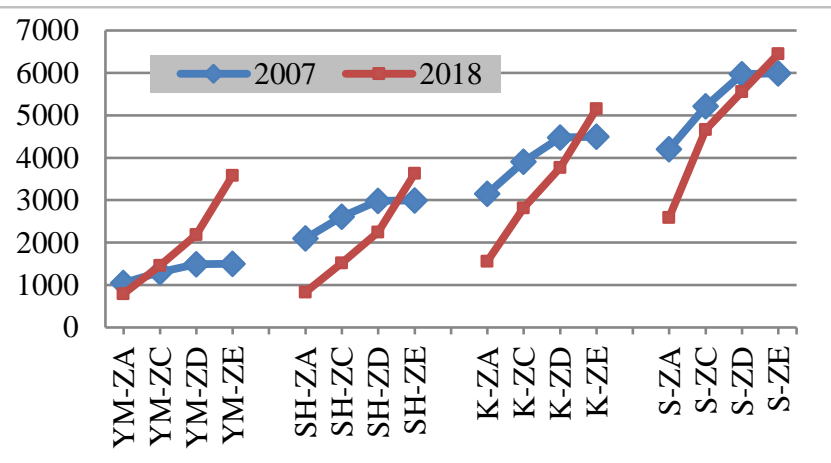

Şekil 5. Yedi katlı binaların konum ve zemin cinsine bağlı değişen taban kesme kuvvetleri $(\mathrm{kN})$

10 katlı binaların taban kesme kuvveti değerlerini karşılaştırdığımızda ise Yenimahalle (YM) konumunda ZCZ2, ZD-Z3 ve ZE-Z4 zemin sinıflarında 2007 yönetmeliğine göre bulunan taban kesme kuvvetlerinin, 2018 yönetmeliği değerlerinden daha düşük, diğer bütün konum ve zemin cinslerinde daha yüksek değerler aldığı görülmüsstür (Şekil $6)$.

TBDY-2018'de çok büyük olmayan depremlerde, dolgu duvarı veya cephe hasarının azaltılması amaciyla, gevrek malzemeden yapılmış dolgu duvarları ile bunların bağlandığ çerçeve elemanları arasında esnek derz yapılması koşuluyla, izin verilen etkin göreli kat ötelemesi iki katına çıkarılmıştır. $\mathrm{Bu}$ çalışmada yaptığımız analizlerde de duvar ve çerçeve arasını esnek derzli kabul edildiğinden maksimum etkin göreli kat ötelemesi sınır şartını daha rahat sağladığı tespit edilmiştir.

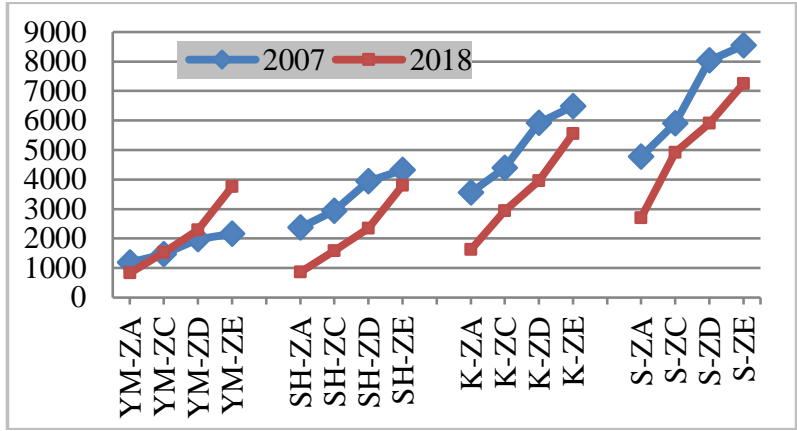

Şekil 6. On katlı binaların konum ve zemin cinsine bağlı değişen taban kesme kuvvetleri $(\mathrm{kN})$

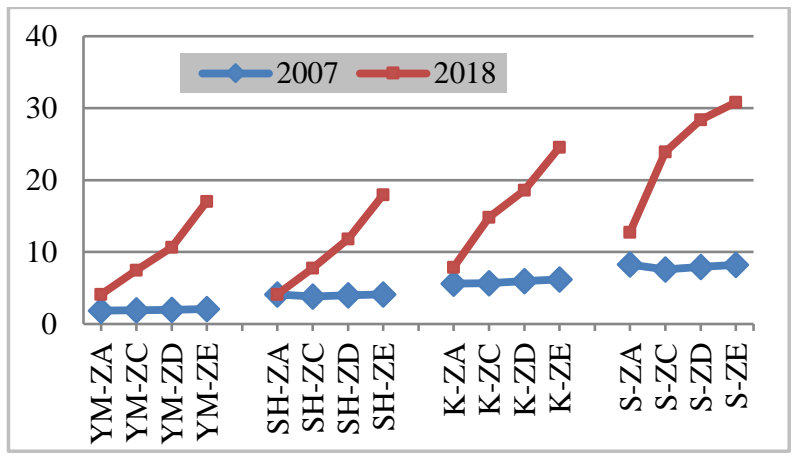

Şekil 7. Dört katlı binaların konum ve zemin cinsine bağlı değişen maksimum etkin göreli kat ötelemeleri (mm)

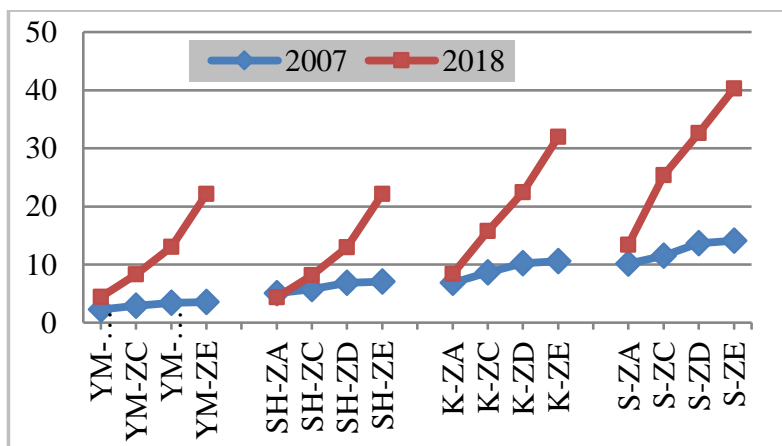

Şekil 8. Yedi katlı binaların konum ve zemin cinsine bağlı değişen maksimum etkin göreli kat ötelemeleri $(\mathrm{mm})$

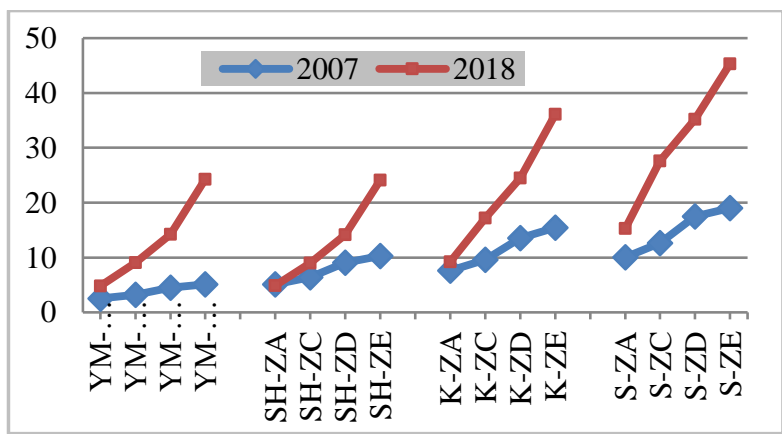

Şekil 9. On katlı binaların konum ve zemin cinsine bağlı değişen maksimum etkin göreli kat ötelemeleri

TBDY-2018'e göre yapılan analizlerde, maksimum etkin göreli kat ötelemesi değerlerinin TDY-2007'ye göre daha büyük olduğu ve bu farkın her yükseklikteki binada ve her 
konumda, güçlü zeminden zayıf zemine doğru gittikçe arttığı tespit edilmiştir (Şekil 7-8-9).

\section{SONUÇ VE ÖNERILER}

Dört farklı konumda ve her konumda 4 farklı zemin cinsi olduğu varsayılarak TBDY-2018 ve TDY-2007 esaslarına göre tasarlanmış 4 katlı, 7 katlı ve 10 katlı konut binalarında spektrum eğrileri, taban kesme kuvvetleri ve maksimum etkin göreli kat ötelemelerinin değerlendirilmesine ilişkin sonuçlar aşağıda verilmiştir;

1. TBDY-2018'e göre yapılan analizlerde bütün binalarda, yap1 doğal titreşim periyot değerlerinde, TDY-2007'ye oranla \% 41-43 arası bir artış olmuştur. Burada TBDY2018'in hesap esaslarına göre yapılan bina tasarımlarında etkin kesit rijitliklerinin dikkate alınmasının zorunlu hale gelmesiyle, yatay deplasman değerlerinde önemli artış olduğu gözlemlenmiştir.

2. TDY-2007'ye göre yapılan analizlerden elde edilen taban kesme kuvvetleri incelendiğinde 4 katlı binalarda aynı konumda, zemin sınıfı, güçlüden zayıfa doğru değiştiğinde değerlerde kayda değer bir artış olmadığ görülmüştür. Bununla birlikte artışın sadece deprem bölgesi değişimlerinde yaşandığ 1 , buna karşın TBDY2018'e göre yapılan analiz sonuçlarında, zemin sınıfının aynı şekildeki değişimlerinde taban kesme kuvvetinin önemli artışlar gösterdiği görülmektedir. Yedi katlı binalarda, bütün analizlerde ZE-Z4 zemin sınıfında yeni yönetmeliğin eski yönetmeliğe nazaran daha yüksek değerler verdiği, 10 katlı binalarda ise taban kesme kuvveti sonuçlarına bakıldığında Yenimahalle hariç bütün konum ve zemin cinslerinde 2018 yönetmeliğinin eski yönetmeliğe nazaran daha düşük değerler verdiği görülmüştür. Genel olarak yeni yönetmelikte, kat sayısı arttıkça taban kesme kuvvetinin eski yönetmelikle elde edilen taban kesme kuvvetinden daha düşük değerler aldığ 1 ve bütün analizlerde yeni yönetmeliğin ZA-Z1 sınıfı zeminlerde 2007 yönetmeliğinden daha düşük değerler verdiği görülmüştür. Bu yeni yönetmeliğin sert zeminlerde daha düşük ivme değerleri tanımladığını göstermektedir.

3. TBDY-2018'e göre yapılan analizlerde, maksimum etkin göreli kat ötelemesi değerlerinin TDY-2007'ye göre çok daha yüksek olduğu ve farkın her yükseklikteki binada, her konumda, güçlü zeminden zayıf zemine doğru gittikçe arttığı görülmüştür. TBDY-2018'de dolgu duvarları ile bunların bağlandığı çerçeve elemanları arasında esnek derz yapılması koşuluyla izin verilen etkin göreli kat ötelemesi iki katına çıkarılmıştır. $\mathrm{Bu}$ çalışmada yapılan analizlerde de duvar ve çerçeve arasını esnek derz kabul edildiğinden maksimum etkin göreli kat ötelemesi sınır şartı daha rahat sağlanmıştır. Ayrıca kat içindeki maksimum etkin göreli kat ötelemeleri, her iki yönetmelik sonucuna göre 4 ve 7 katlı binalarda 2. katta, 10 katlı binalarda 3. katta oluşmuştur.
4. Bu çalışmada, 3 farklı bina yüksekliğinde, simetrik, süneklik düzeyi yüksek perdeli çerçeveli taşıyıcı sisteme sahip konut türünde binalar tercih edilmiştir. Perdeli sistem yerine çerçeve sistemli, düzensizlikler içeren, konut türü dışındaki binalar ya da yüksek binalar sınıfına giren binalar tercih edilerek karşılaştırma konularına yeni kazanımlar eklenebilir.

\section{KAYNAKÇA}

[1] Türkiye Deprem Bölgelerinde Yapılacak Binalar Hakkında Yönetmelik, (2018), Afet ve Acil Durum Yönetim Başkanlığı, Ankara.

[2] Öztürk, M., "2018 Türkiye Bina Deprem Yönetmeliği ve Türkiye Deprem Tehlike Haritası ile İlgili İç Anadolu Bölgesi Bazında Bir Değerlendirme", Selçuk-Teknik Dergisi, 17(2),32-33. (2018).

[3] Tunç, G., ve Tanfener, T., "2007 ve 2016 Türkiye Bina Deprem Yönetmeliklerinin Örneklerle Mukayesesi”, 3.Ulusal Yap1 Kongresi ve Sergisi Teknik Tasarım, Güvenlik ve Erişebilirlik, TMMOB Mimarlar Odası Ankara Şubesi, (2016).

[4] Erdem, M. M., Bikçe, M., "Maksimum Azaltılmış Göreli Kat Ötelemelerinin Güncel (TDY-2007) ve Yeni Yönetmelik Taslağına (TBDY-2018) Göre Mukayesesi”, Çukurova Üniversitesi Mühendislik Mimarlık Fakültesi Dergisi, 32 (2), 253-262, (2017).

[5] Elçi, H. ve Göker, K.A., "Deprem Yönetmeliklerinin (TDY 2007 ve TBDY 2018) Betonarme Kolonların Deprem Performansı Açısından Karşılaştırılması", International Journal of Scientific and Technological Research ISSN 2422-8702 (Online), 4(6), 9-21, (2018).

[6] Koçer, M., Nakipoğlu. A., Öztürk, B., Al-Hagri, G. M., Arslan, H. M., "Deprem Kuvvetine Esas Spektral İvme Değerlerinin TBDY-2018 ve TDY-2007'ye göre Karşılaştırılması”, Selçuk-Teknik Dergisi, 17(2),43-58, (2018).

[7] Keskin, E , Bozdoğan, K . "2007 ve 2018 Deprem

Yönetmeliklerinin Kurklareli İli Özelinde Değerlendirilmesi". Kırklareli Üniversitesi Mühendislik ve Fen Bilimleri Dergisi, 4: 74-90, (2018 ).

[8] Dalyan, İ, Şahin, B . "Mevcut Betonarme Bir

Binanın 2007 ve 2018 Deprem Yönetmeliklerine Göre Deprem Yükleri Altındaki Taşıyıcı Sistem Perfomansının Değerlendirilmesi". Türk Deprem Araştırma Dergisi, 1: 134147, (2019).

[9] Ulutaş, H . "DBYBHY (2007) ve TBDY (2018) Deprem Yönetmeliklerinin Kesit Hasar Sınırları Açısından Kiyaslanması". Avrupa Bilim ve Teknoloji Dergisi, DOI: 10.31590/ejosat.620827, 17: 351-359, (2019).

[10] Türkiye Deprem Bölgeleri Haritası, Afet İşleri Genel Müdürlüğü Deprem Araştırma Dairesi, (1996).

[11] Deprem Bölgelerinde Yapılacak Binalar Hakkında Yönetmelik, (2007), Bayındırlık ve İskan Bakanlığı, Ankara. [12] İdecad Statik, (2019), Yapısal Analiz Programı, Versiyon 10-0196 Statik.

[13] Türkiye Deprem Tehlike Haritası, Afet ve Acil Durum Yönetimi Başkanlığı, (AFAD, 2018). 